artist-brings out chiefly the comical aspects of animal life may, perhaps, be more appreciated by the general reader.

A chapter on cures for snake-bite is intended to illustrate the play of vernacular superstition rather than to explain the rational basis of European methods of treatment, but since the history of acquired immunity to snake-poison and of the attendant discovery of antivenine is outlined, it is a pity, perhaps, that the names of Sewall and Calmette were not mentioned among the great original dramatis personae.

\section{THE NEW ISSUE OF THE BRITISH PHARMACOPAEIA.}

THE publication of a new issue of the British Pharmacopceia is an event of considerable importance to the medical as well as to the pharmaceutical world. It reflects, so far as is compatible with official recognition, the changes that have taken place in the opinion of physicians as to what drugs and preparations are of sufficient importance to be included in it, and the opinion of pharmacists as to how such drugs are to be defined and such preparations of them to be made. Though the Medical Act of 1858 requires that the General Medical Council shall cause the British Pharmacopœia to be published, it is well known that the labour of revision, in so far as it relates to the monographs and appendices in the work, has been carried out, practically in its entirety, by the Committee of Reference in Pharmacy to which somewhat scanty acknowledgment is made in the preface. That to pharmacists alone this most responsible part of the revision can safely be entrusted has long been officially recognised in most countries in which a pharmacopœia is published, and the opinion has been freely expressed that the time has now arrived when British pharmacists should occupy a more satisfactory position in the revision of future issues of the British Pharmacopœia.

Such of the articles and preparations of the Indian and Colonial Addendum of rgoo as were deserving of retention have now been embodied in the text, but it is observable that a large proportion has been dropped; of those retained the following alone are used to some extent in this country: couch grass, arnica flowers, black catechu, cotton-root bark, grindelia, ghatti gum, rhizome and resin of Indian podophyllum, and black haw bark.

The additions to the Pharmacopœia are not numerous, there being only forty-three. The most important of these are acetone, acetylsalicylic acid, picric acid, adrenalin, barbitone (diethylbarbituric acid, also known as veronal), benzamine lactate (beta-eucaine lactate), calcium lactate, cantharidin, chloral formamide, cresol, diamorphine hydrochloride (diacetylmorphine hydrochloride), ethyl chloride, guaiacol, guaiacol carbonate, hexamine (hexamethylenetetramine), ipomoea, root (the so-called Mexican scammony root from which scammony resin may now be obtained), solution of adrenalin hydrochloride, NO. $236 \mathrm{I}$, VOL. 94] solution of formaldehyde, solution of formaldehyde with soap, methyl salicylate, methylsulphonal, phenolphthalein, resorcin, acid sodium phosphate, strontium bromide, and theobromine and sodium salicylate (diuretin). The number of new synthetic drugs is therefore remarkably small, and affords an indication of the opinion of the medical profession of the permanent value of the host of such remedies that have been introduced during recent years.

The omissions, 166, are far more numerous, the following being the most important of the drugs discarded: arnica rhizome, bismuth oxide, gamboge, cantharis (now replaced by cantharidin), coca leaves (now replaced by cocaine and its hydrochloride), saffron, galbanum, jaborandi leaves (now replaced by pilocarpine nitrate), hops, mezereon bark, calabar beans (now replaced by physostigmine sulphate), elder flowers, sarsaparilla, scammony and mustard. As a general rule the preparations of discarded drugs have also been omitted; of other preparations reference may be made to the class of concentrated liquors, all of which have been deleted.

Alterations in strength are not numerous, nor are they, with a few exceptions, important; many of them have been necessitated by the endeavour to comply with the recommendations of the Brussels International Conference, an endeavour which has for practical purposes been effectively accomplished. The greatest change has been in tincture of strophanthus, which is now four times as strong as it used to be, and the most far-reaching that of tincture of opium, which has been increased in strength by one-third.

Perhaps the most conspicuous change in the Pharmacopoia is the omission (except from the doses) of all imperial weights and measures. The dual system of the issue of 1898 , which was a constant source of trouble, has therefore been abolished, and the formulæ are in general now arranged to produce Ioo or rooo parts by weight or volume. The percentage composition is thus evident at a glance, and considering the present extensive use of metric weights and measures no inconvenience should arise from the change. The use of the term "millilitre" instead of "cubic centimetre," appears strange at first, but it must be admitted that the millilitre, though not in general use, is the more strictly correct designation. "Mil," "decimil," and "centimil," convenient contractions that have been recognised by the Board of Trade, are used in stating the doses. A "drop" is no longer a vague and variable quantity; in accordance with the International Agreement the external diameter of the dropping tube is to be exactly 3 millimetres, 20 such drops of water at $15^{\circ}$ being equivalent to $\mathrm{r}$ millilitre.

Volumetric solutions are now designated as $\mathrm{N} / \mathrm{r}, \mathrm{N} / \mathrm{ro}$, etc., in agreement with common usage. The directions for preparing these solutions have been omitted from the appendices, the statement only of the strength corresponding to the designation being made. No fewer than twenty-five volumetric solutions are employed in 
the present Pharmacopoia as compared with eight in the last. Temperatures are expressed in degrees centigrade, and the atomic weights adopted are those agreed upon for 1914 by the International Committee.

When the monographs are scrutinised it is seen that scarcely any have escaped alteration of some kind, and that most have been notably improved. The verbosity of the last Pharmacopoia has been replaced by a terseness that is sometimes almost harsh. Whenever possible the monograph contains in the first few lines a definite statement of the minimum permissible percentage of pure substance, alkaloid, etc., and a means is given by which this may be ascertained. Particular attention is devoted to the proportion of those dangerous impurities, lead and arsenic, that may not be exceeded. No fewer that fifty-six such lead and ninety-one arsenic limits have thus been introduced; the methods for determining them are given in the appendices, and are those originally introduced by Mr. C. A. Hill and now in general use in pharmaceutical laboratories.

The monographs for the volatile oils, fixed oils, fats, etc., have also undergone thorough revision. In most of them the limits of specific gravity, optical rotation, and refractive index are stated; determinations of acid value, saponification value, iodine value, ester content, and alcohol content are frequently given, in addition to which the assay for a particular constituent, such as cineol, cinnamic aldehyde, etc., is also introduced where desirable.

The monographs of crude drugs and galenical preparations have undergone a similar thorough revision. In the former the most conspicuous change has been the extension of the microscopical characters; these are fully described whenever the information is important for the identification of the drug, and in many cases the microscopical characters of the powder are also given. The principle of standardisation has been extended, and the assay processes of the last Pharmacopoia have been revised in the light of recent investigations.

Allusion has been already made to some of the additions and alterations in the appendices. The articles and reagents used in chemical testing are, with few exceptions, defined as those "of the British Pharmacopœia" or "of commerce, pure." Appendix xvii. consists of a list of abbreviated Latin names introduced as the result of a communication from the chairman of the United States Pharmacopoial Convention; this is a distinctly novel feature. No suggestion is made that either pharmacists or physicians should employ these abbreviations, and it remains to be seen whether the introduction will have any practical value.

Looking at the Pharmacopœia as a whole, it is evident that the general principle on which the revision has been carried out has been that of substituting practical for theoretical or academical standards. Many of the methods adopted have already been subjected to prolonged trial in pharmaceutical laboratories, and the limits fixed are those which have been found to be practically attainable. The reports that have from time to time been issued show that most of the suggestions and data for these improvements have emanated from the Committee of Reference in Pharmacy, and to this body full credit should be given for the revision it has accomplished successfully.

\section{SYNTHETIC DRUGS IN GREAT BRITAIN.}

$A^{T}$ the commencement of the war, the sudden A cessation of all supplies of synthetic drugs from German sources rendered it probable that the stocks in hand in this country would not be sufficient to meet the demand until such time as the English manufacturers could adapt themselves to the altered conditions. Early in September, therefore, the Admiralty asked the Imperial College of Science and Technology to prepare for them $30 \mathrm{lb}$. of phenacetine, $50 \mathrm{lb}$. of hexamethylenetetramine, and $I_{2} \frac{1}{2} \mathrm{lb}$. of $\beta$-eucaine. For the past five months the staff and research students of the Organic Department of the college have been engaged in carrying out this request, with the result that the required quantities have now been forwarded to the Naval Hospitals at Haslar, Chatham, and Plymouth.

With the exception of salvarsan, which is being made by Messrs. Borroughs and Wellcome, and aspirin, which is now being made by Messrs. Boots, Ltd., no synthetic drugs have been manufactured previously in this country. As regards drugs from natural sources, however, it is probable that English firms have always produced very much more than the German firms.

Phenacetine is a product of the Baeyer firm at Elberfeld and has never been made before in this country. It is probable that all the phenacetine in commerce emanates from this firm, although it is understood that the immediate needs of this country are now being met by the importation of considerable quantities of this drug from the United States of America.

After numerous experiments, the method found most suitable to the conditions prevailing in a scientific laboratory was that shown by the series :-

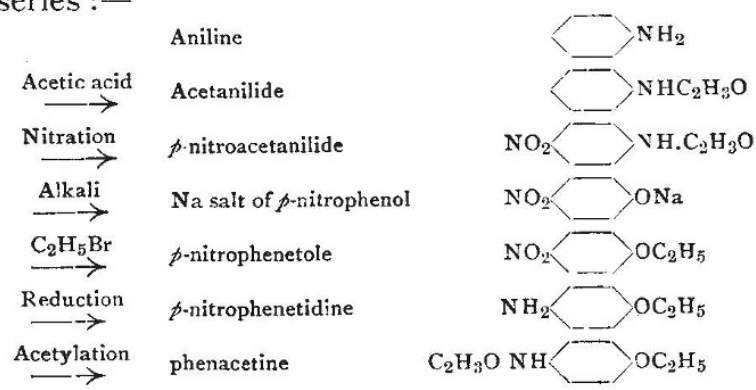

The various operations were so arranged that ultimately $\mathrm{I} \frac{1}{2} \mathrm{lb}$. of pure phenacetine were prepared daily, the by-products being recovered and used again.

Hexamethylenetetramine.-The preparation

NO. $236 \mathrm{I}$, VOL. 94] 